\title{
Vestígios de cooperação e solidez na sociedade líquido-moderna: um olhar sobre um centro de tradições gaúchas
}

\section{A glimpse on a gaucho traditions center in liquid - modern society: traces of cooperation and soundness}

Larissa Medianeira Bolzan

Doutoranda em Administração, Linha de Pesquisa: Gestão de Pessoas, na Universidade Federal do Rio Grande do Sul. Mestre e Bacharel em Administração pela Universidade Federal de Santa Maria, Rio Grande do Sul, Brasil.

larissambolzan@gmail.com

Alice Schaffer da Rosa

Graduada em Administração de Empresas pela Universidade Federal do Rio Grande do Sul. Mestrando Acadêmico em Gestão de Pessoas na UFRGS. Graduação incompleta em História Bacharelado na UFRGS, Rio Grande do Sul, Brasil.

alicesrosa@gmail.com

Carmem Ligia lochins Grisci

Doutora em Psicologia. Professora PPGA/EA/UFRGS. Pesquisadora CNPq - 1D., Rio Grande do Sul, Brasil.

carmem.grisci@ufrgs.br

\section{Editor Científico: José Edson Lara}

Organização Comitê Científico

Double Blind Review pelo SEER/OJS

Recebido em 20.11.2014

Aprovado em 22.03.2016

Este trabalho foi licenciado com uma Licença Creative Commons - Atribuição - Não Comercial 3.0 Brasil
} 


\section{RESUMO}

No contexto da sociedade líquido-moderna, em que palavras como velocidade, flexibilidade, imediatismo, desapego, mobilidade e rentabilidade circulam comprimindo o tempo numa "cultura da urgência" (Bauman, 2007; Sennett, 2012), julga-se pertinente indagar: que vestígios de cooperação e de solidez relativos à experimentação do tempo poderiam se fazer notar? A fim de responder essa indagação, buscou-se levantar e analisar a existência de vestígios de cooperação e de solidez relativos à experimentação do tempo em um CTG (Centro de Tradições Gaúchas). Elaborou-se uma pesquisa qualitativa exploratória, realizada por meio de um estudo de caso singular, em que a unidade de análise é o $35 \mathrm{CTG}$, onde foram realizadas entrevistas narrativas com os associados. O estudo permitiu conhecer quais são os elementos, alguns dos rituais e a forma como estes operam no contexto do caso do $35 \mathrm{CTG}$, tornando palpável o contexto no qual encontramos os vestígios da cooperação e da solidez.

Palavras-Chaves: Cooperação; Solidez; CTG.

\section{ABSTRACT}

In the context of the modern-liquid society, where such words as velocity, flexibility, profitability, immediacy, detachment and mobility are in the order of the day, and time is compressed in a "urgency culture", is considered important to ask: which traces of cooperation and solidity, related to the way time is experienced could be noticed? To answer that question, we aimed to identify and analyze the existence of cooperation and solidity traces related to time experimentation in a Center for Gaúcho Traditions (CTG). A qualitative exploratory research was conducted through singular case study in the 35 CTG, where narrative interviews were conducted with the CTG's members. The study has allowed us to know the elements, some of the rituals and the way they operate in the context of the CTG, where traces of cooperation and solidity were found.

Keywords: Cooperation; Solidity; CTG. 


\section{INTRODUÇÃO}

Líquido-moderna é como Bauman (2007, p. 7) denomina a sociedade em que as condições sob as quais agem seus membros mudam num tempo mais curto do que aquele necessário para a consolidação, em hábitos e rotinas, das formas de agir. A liquidez da vida e a da sociedade se alimentam e se revigoram mutuamente. A vida líquida, assim como a sociedade líquido-moderna, não pode manter a forma ou permanecer em seu curso por muito tempo.

$\mathrm{Na}$ vida assim caracterizada, num "ambiente líquido, imprevisível e de fluxo rápido, precisamos, mais do que nunca, de laços firmes e seguros de amizade e confiança mútua" (Bauman, 2007, p. 140).

Os atuais modos de trabalhar, apoiados na ideia de curto prazo e flexibilidade, dificultam a construção dos laços de confiança e ajuda mútua, vindo, inclusive, a comprometer o caráter, conforme alerta Sennett (2012). Peculiar aos modelos flexíveis de gestão que se evidenciam em ambientes competitivos, se enaltece a lógica que aponta o sujeito como senhor de suas escolhas e de seu estilo de vida, algo de nenhum modo pessoal, mas relativo a uma possibilidade de vida, a um modo de existência, ensina Deleuze (1998).

Frente a esse cenário onde palavras de ordem como velocidade, flexibilidade, rentabilidade, imediatismo, desapego e mobilidade circulam comprimindo o tempo numa "cultura da urgência" (Bauman, 2007; Sennett, 2012; Silva, Mendes \& Alves, 2015), julga-se pertinente indagar: que vestígios de cooperação e de solidez relativos à experimentação do tempo poderiam se fazer notar? A fim de responder essa indagação, objetivou-se levantar e analisar a existência de vestígios de cooperação e de solidez relativos à experimentação do tempo em um CTG (Centro de Tradições Gaúchas). Criado para acolher as manifestações da tradição gaúcha, a identificação com os símbolos e os rituais da tradição é o único requisito para a associação (Ribeiro, 1997; Luvizotto, 2010). Compreendido como algo a "servir de pano de fundo para a sociabilidade, relações sociais coletivas e duradouras estabelecidas a partir da identidade cultural dos gaúchos" (Luvizotto, 2010. p. 14), o CTG se mostrou um campo profícuo ao presente estudo, que resulta de uma 
pesquisa exploratória, no sentido de possibilitar vislumbrar vestígios de solidez durabilidade e permanências -, e de cooperação.

O artigo encontra-se assim estruturado: a essa introdução seguem-se a revisão da literatura, os procedimentos metodológicos, a apresentação e análise dos resultados e, por fim, as considerações finais

\section{REVISÃO DA LITERATURA}

\subsection{A vida líquida na sociedade líquido-moderna}

Velocidade. Intensidade. Expectativa. Incerteza. Ansiedade. Tais termos revelam sentimentos de quem transita pela sociedade líquido-moderna. Bauman (2007) se refere à vida líquida como uma série de reinícios, em uma espécie de "destruição criativa", uma vida que não pode ficar parada, devendo modernizar-se, recriar-se, reiniciar. Para Haroche (2015), as condições contemporâneas da vida mental se prendem à tecnologia, à velocidade, à aceleração, induzindo uma ausência de reflexão ligada à rapidez, à instantaneidade, à imediatidade. Nessas condições, realizações individuais não se solidificam, pois as condições de ação e estratégias de reação rapidamente se tornam obsoletas. Como diz Bauman (2011, p.8), os tempos líquidos 'ffluem', 'escorrem', 'esvaem-se', 'respingam', 'transbordam', 'vazam', 'inundam' [...] contornam certos obstáculos, dissolvem outros e invadem ou inundam seu caminho". A obsolescência e o descarte, característicos desses tempos, fazem crer que a lealdade não é motivo de orgulho, a proposta corrente é "ligar-se ligeiramente a qualquer coisa que se apresente" [e] "deixá-la ir embora graciosamente" (Bauman, 2007, p. 12).

O objetivo de um indivíduo na sociedade líquido-moderna é o sucesso, que se exprime em um propósito declarado de vida individual, de busca por desafios e pela própria forma de persegui-los, tendo a utilidade como valor prioritário (Palese, 2013). Os indivíduos, aos quais Bauman (2007), Amaral, S. C. de S., Pinho, L. G., Martinez, S. A., e Nascimento, G. do. (2014) e ainda Zarur e Campos (2015) se referem, são semelhantes entre si e isso se dá pelo fato de seguirem uma mesma estratégia de vida e usarem símbolos comuns para convencerem uns aos outros de que assim o fazem. Nesse sentido, Gaulejac (2007, p. 299) postula que a honra, o desinteresse e a solidariedade são valores de base necessários para a vida social. Os homens deveriam preocupar-se mais com essa moral do que com o sucesso individual. Em vez de querer 'por as pessoas no trabalho', para mobilizá-las 
na corrida para a produtividade seria tempo de encontrar novamente o prazer da gratuidade, da troca e da partilha sem cálculo.

Para Bauman (2007), no cerne do conceito de cultura se encontra também a aceitação de uma relação social assimétrica. Refinados e grosseiros, os que agem e os que sofrem o impacto da ação. Um objeto seria cultural a depender de sua permanência e o destino de produtos culturais não deveria dissolver-se em um processo de consumo instantâneo.

\subsection{Cooperação}

Apesar de os modos de trabalhar condizentes com a vida líquida-moderna dificultarem a construção dos laços de confiança e ajuda mútua, Gorz (2005) sustenta que indivíduos os quais cooperam e se ajustam livremente, tendem a se superar. Ao observar que a sociedade moderna está desabilitando as pessoas na condução da vida cotidiana, Sennett (2012), argumenta em prol da cooperação, definindo-a como "uma troca em que as partes se beneficiam" (p. 15-16). Gaulejac (2007) aponta que trocas simbólicas são a base para as relações sociais, pois o símbolo é um modo de selar um acordo entre os homens, com base em relações harmônicas entre o interesse pessoal e o geral.

Nesse sentido, os rituais permitem a "cooperação expressiva na religião, no trabalho, na política e na vida comunitária" (Sennett, 2012, p.30). Ao desempenhar um rito transmitido pela tradição, por exemplo, o celebrante tem a impressão de deixar a esfera do tempo à margem. Embora pareça que o ritual seja externo ao indivíduo, não se trata de apenas repeti-lo, pois os rituais não são um comportamento estanque. Em concordância, Gaulejac (2007) evidencia que quando determinada atividade faz sentido para o sujeito, sua adesão está adquirida e os esforços voltam-se à mobilização de capacidades reflexivas e criativas.

Acerca das contribuições individuais, cabe explorar os saberes que não podem ser inteiramente ensinados ou traduzidos em conhecimentos formalizáveis, em procedimentos homologados ou em ciência. O saber "repousa sobre as capacidades expressivas e cooperativas que não se pode ensinar, sobre uma vivacidade presente na utilização dos saberes e que faz parte da cultura do cotidiano" (Gorz, 2005, p.19). Há, também, uma relação entre saberes e cultura, sendo a riqueza de uma cultura diretamente proporcional aos saberes comuns que a tecem, que a 
permitem integrar, transformar conhecimentos e novos saberes. Nesse sentido, Gorz (2003) indica a naturalização dos saberes, quando se esquece de que houve aprendizagem e se acredita tratar-se de uma habilidade nata.

Em concordância, Chanlat (2011) postula que o peso da história é sempre o "pano de fundo da relação"; todos os indivíduos são conectados entre si e essa conexão se dá, em muito, graças a uma ritualização e a um processo de comunicação. Nesse contexto, destaca a identidade sociocultural, da relação que se estabelece entre grupos. Para o autor, todo o grupo se torna diferente quando comparado a outro grupo. No Rio Grande do Sul, por exemplo, observa-se um forte regionalismo e uma forte influência da tradição gaúcha nas ações e costumes do povo familiarizado com este Estado.

Além disso, de acordo com Luvizotto (2010, p.19) a "cultura gaúcha e suas expressões estão alicerçadas em tradições, em conhecimentos obtidos pela convivência em grupo, somados a diversos elementos, entre eles, os históricos e os sociológicos". É assim que seu legado é transmitido às gerações seguintes, ainda que sujeito a mudanças próprias de cada época e circunstância. Luvizotto (2010) destaca que o culto à tradição é uma reação às transformações da sociedade e à influência de outras culturas.

\subsection{0 tradicionalismo}

O "ser gaúcho" não é caracterizado somente por aquele nascido no Rio Grande do Sul; este seria apenas o sul-rio-grandense. O "ser gaúcho" é um sentimento que independe de território,

ultrapassa as barreiras geográficas, a filiação e a origem ancestral e passa a ser um sentimento de identificação com uma cultura arraigada em valores rurais, campeiros, mas que se manifesta também em meio urbano, buscando resgatar valores como honra, liberdade e bravura (Luvizotto, 2010. p. 31).

O "ser gaúcho", inundado de sentimento de tradição, é (re)inventado e transmitido pelas várias gerações. Luvizotto (2010) considera a existência de diversas maneiras de transmitir tradições, argumentando que, ao longo da história, o homem se utilizou de gestos, expressões corporais e do espetáculo para manter suas tradições. 
As tradições gaúchas não são totalmente isoladas das mudanças vivenciadas pela sociedade contemporânea. A transmissão da cultura e de sua expressão, seja através da dança, do tempero, da música, da vestimenta (e suas regras), do penteado, trata-se da transmissão de um saber imaterial, lúdico e com valor simbólico à continuidade da tradição (Luvizotto, 2010).

\section{MÉTODO}

O presente estudo resulta de uma pesquisa qualitativa exploratória, realizada por meio de um estudo de caso singular, em que a unidade de análise é o $35 \mathrm{CTG}$, entendido aqui como um sistema de relações sociais (Stake, 2005) e não apenas como uma organização.

A coleta de dados constituiu-se de 13 entrevistas narrativas com associados do 35 CTG. De acordo com as etapas da entrevista narrativa proposta por Jovchelovitch e Bauer (2005), foi apresentado o tópico central - a tradição como parte da vida - a fim de que os narradores apresentassem seu envolvimento com o movimento tradicionalista. $\mathrm{Na}$ sequência da narração, foram feitas perguntas imanentes (que buscavam dados específicos da história de forma a torná-la mais clara e compreensível) e perguntas exmanentes (que buscavam a relação da história ou de suas partes com questões mais amplas da pesquisa). Estas perguntas não seguiram um roteiro fixo, considerando que cada história gera seus próprios questionamentos.

Após as perguntas foram apresentadas aos entrevistados as três imagens a seguir, relativas ao tradicionalismo gaúcho, sempre na mesma ordem, para que, a partir delas, verbalizassem a que a imagem Ihes remetia.

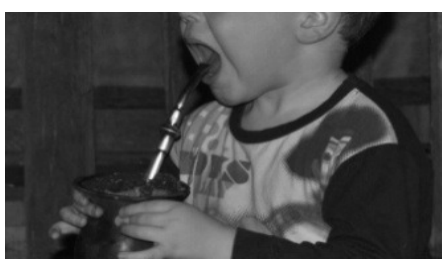

Figura 01: Menino com Chimarrão

Fotografia de Luiz Carlos Muller

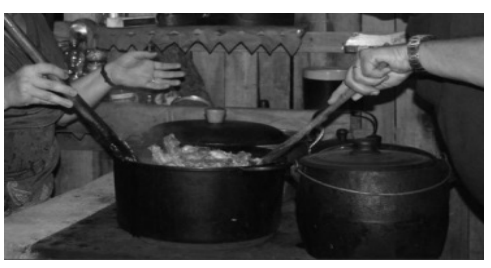

Figura 02: Preparo do Alimento Fotografia de Luiz Carlos Muller

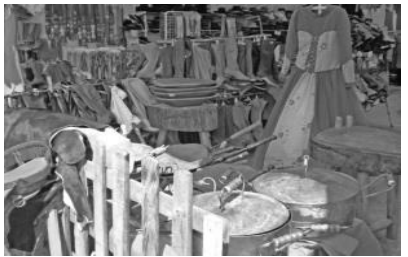

Figura 03: Bolicho de Campanha Fotografia de Luiz Carlos Muller

Para analisar as narrativas, utilizou-se a proposta de Schütze, 1977 e 198, como citado em Jovchelovitch e Bauer, 2005. Assim, seguiram-se seis passos: a 
transcrição detalhada; a divisão do texto em material indexado e não indexado; a construção da trajetória ou o ordenamento dos acontecimentos; a análise do conhecimento através das dimensões não indexadas; as comparações entre trajetórias individuais; e a construção das trajetórias coletivas inseridas no contexto especifico. Para fins de compreensão, esclarece-se que foram consideradas como proposições indexadas aquelas que têm referência concreta (quem, o que, quando, onde e por quê) e, como referências não indexadas, as proposições que se referem a sentimentos, percepções, valores, juízos, opiniões.

Utilizaram-se pseudônimos retirados do vocabulário gaúcho, atribuídos aos entrevistados devido às suas características. Vivente, Capataz, Campeira, Guri de CTG, Gaiteiro, Patroa, Primeira Prenda, Bolicheiro, Mãe de Prenda, Tropeiro, Prenda Farroupilha, Segunda Prenda e Mulher Estancieira.

Definiu-se o CTG como unidade de análise, pois o presente trabalho objetiva acolher as manifestações da tradição gaúcha e é nele que faz sentido toda a atividade que envolve os símbolos e rituais dessa tradição. O CTG é destinado a manter a sociabilidade e o vínculo daqueles que se identificam como gaúchos. Atualmente é no CTG que se recriam referências tradicionais, ampliando-as, sob aspecto lúdico, "não para servir de mecanismo de coordenação das práticas sociais, mas sim para servir de pano de fundo para a sociabilidade, relações sociais coletivas e duradouras estabelecidas a partir da identidade cultural dos gaúchos" (Luvizotto, 2010. p. 14). No CTG também se encontram discussões e análises a respeito da tradição gaúcha como um fator de organização de ações e relações de trabalho duradouras necessárias à constituição de uma coletividade, características já encontradas no trabalho de Luvizotto (2010).

Juridicamente, o CTG é uma entidade civil de direito privado, sem fins lucrativos, cujo funcionamento é regido por um estatuto baseado na carta de princípios do Movimento Tradicionalista Gaúcho. Ao desempenhar suas atividades, o CTG tem o dever de observar os princípios da legalidade, impessoalidade, moralidade, publicidade, economicidade e eficiência. O caráter de ludicidade atribuído às tradições (re)inventadas no CTG é o fio condutor de inúmeras relações que se estabelecem nesse cenário, sendo também o combustível de todas as práticas e rituais vivenciados ali. 
Fundado em 24 de abril de 1948, o 35 CTG foi o primeiro CTG do mundo. Embora herdeiro de outras formas de organização tradicionalista gaúcha, foi o pioneiro a estruturar o centro de tradições como espaço social da vivência da cultura gaúcha. Seu espaço possibilita o estudo das danças, das poesias, das falas do gaúcho, dos hábitos e da história. O objetivo é perpetuar as manifestações da cultura e tradições gaúchas com a maior precisão possível para o público nacional e internacional.

\section{RESULTADOS}

\subsection{Vestígios de cooperação e solidez na sociedade líquido-moderna}

Completamente apaixonados pela tradição e pelo movimento tradicionalista, assim se apresentaram os narradores deste estudo. Tal sentimento gera busca de conhecimento a respeito da tradição e de seus elementos, bem como os leva a praticar e perpetuar os usos e costumes. Para os narradores, o CTG é um lugar de compartilhamento, havendo responsabilidade e confiança entre seus associados.

O CTG é frequentado por toda a família. E, em nome da família, os entrevistados foram unânimes em expor o desejo de continuidade e permanência da tradição como objetivo de vida. O comprometimento com a tradição associa-se à identificação do sujeito com a atividade, à adesão imediata e aos esforços voltados à mobilização de capacidades reflexivas e criativas a fim de desempenhá-las (Gaulejac, 2007).

Narram que sua contribuição individual é mais visível quando uma criança demonstra interesse pela tradição - dançando em invernadas, usando pilcha, tomando chimarrão ou até mesmo comendo erva-mate. Para eles significa que se criou um ambiente propício a despertar amor pela tradição. llustram isso, a mãe que dá colo ao filho enquanto toma chimarrão; o pai que, pilchado, ouve músicas gaúchas em casa, conta histórias tradicionais e incentiva a família a frequentar o CTG. Para melhor ilustrar, abaixo destaca-se um trecho da narrativa de Bolicheiro:

Meus pais não eram de CTG, eles entraram por causa dos filhos. Começaram a participar no bairro, foi importante eles participarem, até para minha infância, foram doze anos. Meu pai vem aqui e minha filha também está aqui. A harmonia das crianças brincando, os homens conversando, meu pai enche os olhos vendo minha filha dançar, como avô. Antes eu era o filho dançando, agora eu sou o pai e isso é muito importante, ver isso é importante para mim. 
Cabe considerar tais atitudes como trocas simbólicas, base para as relações sociais, responsáveis por selar acordos de significações comuns entre os homens. No caso específico deste estudo, os símbolos comuns são os elementos de solidez - permanência e durabilidade.

Tal como em Luvizotto (2010), os narradores não condicionam o "ser gaúcho" àquele nascido no Rio Grande do Sul, conforme já mencionado. Convergente a isso, Bolicheiro narra:

A meta de vida é continuar com a tradição dos usos e costumes que foram deixados pelos nossos antepassados, nossos avós, homens mais velhos, no caso de galpão, a lida de campo, a influência dos homens mais velhos usando bombacha bem grande, bigode bem grande, tomando chimarrão, na lida do campo, domar o cavalo, dominar o cavalo, andar a cavalo, botar os arreios completos: peiteira, rabicho, mala de ponta, badana. Então isso me influenciou a usar toda a pilcha do peão, colete, bombacha, guaiaca, lenço vermelho no pescoço, na minha vida particular eu tenho mais bombacha que calça jeans.

Outra dimensão que surgiu das narrativas foi o comportamento diferenciado assumido por aqueles envolvidos com o movimento tradicionalista. Os narradores contemplam que os envolvidos com o movimento apresentam valores pessoais diferenciados: humildade, simplicidade, lealdade, respeito, confiança e responsabilidade. Para Bolicheiro

o ensinamento do tradicionalismo influencia no respeito ao outro, ao colega de trabalho, à questão da hierarquia, de uma questão mais tradicional de respeitar a mãe e o pai, os mais velhos, não é uma questão de submissão, é de respeito mútuo mesmo. [...]. No interior funciona assim, é o fio do bigode.

Para Tropeiro, "sem dúvida nenhuma quem participa do CTG é mais confiável, porque segue as regras do tradicionalismo, que tem muitas regras, muitas restrições".

Esse comportamento também foi explorado na narrativa da Primeira Prenda Regional Adulta, que explica:

Nós temos uma criação diferenciada do resto dos jovens da sociedade porque a gente cresce com a Carta de Princípios e a Tese, o Sentido e o Valor do Tradicionalismo. Quando a gente é criança, nossos pais nos passam isso e a gente não percebe. Vai passando o tempo e adapta isso à nossa vida. A gente aprende como lidar com pessoas de outras gerações. 
Para Bauman (2007), os indivíduos são semelhantes entre si por seguirem uma mesma estratégia de vida e usarem símbolos comuns para convencerem uns aos outros de que assim o façam. Do mesmo modo, aqueles que participam do CTG apresentam comportamentos semelhantes e símbolos comuns, com os quais se identificam.

Nesse sentido, narram o CTG como um espaço que não enaltece a fluidez da sociedade líquido-moderna. É como se o líquido fosse obrigado a contornar suas paredes. No CTG, o descarte não é apreciado de modo a "ligar-se ligeiramente a qualquer coisa que se apresente" e "deixá-la ir embora graciosamente" (Bauman, 2007, p. 12).

Relevante no contexto é o fato de que pela primeira vez o 35 CTG teve uma Patroa eleita e reeleita (o patrão é um cargo eletivo, e tem funções semelhantes ao presidente de um clube, segundo Luvizotto (2010), embora o CTG surgisse como um espaço para que os homens do campo pudessem vivenciar e cultivar suas tradições na cidade. No ambiente rural, somente os homens se reuniam no galpão, e a entrada das mulheres se limitava apenas após as reuniões e festejos para fazer a limpeza e a arrumação. Assim, nos dois primeiros anos do CTG 35, este era um espaço só de homens. No entanto, logo os jovens fundadores perceberam o interesse de suas irmãs e namoradas em participar. À época as mulheres enfrentaram resistências de suas famílias, mas passaram a fazer parte das atividades, até que em 2011, uma mulher alcançasse a liderança do CTG.

A mudança da patronagem promoveu maior participação de mulheres e crianças em atividades culturais do CTG. Foram realizadas festas de Páscoa e de Natal para as crianças, geralmente trazidas por suas mães, e foi criada a invernada micuim (grupo de dança para crianças menores de 5 anos). Conforme as narrativas, essas ações ainda foram responsáveis por trazerem novos associados para o CTG. As mudanças também alcançaram outras questões, assim descritas por Patroa:

No início não foi muito fácil, porque o preconceito é muito forte na sociedade. As pessoas não se declaram preconceituosas, mas elas são. Então eu quebrei um paradigma muito forte aqui dentro, porque o 35 era comandado por homens mais velhos e todos da elite da sociedade gaúcha.

Até mesmo as regras do CTG começaram a se adaptar a um novo contexto, despindo-se de restrições que limitavam o acesso de homossexuais, por exemplo, em que pese este ainda ser um aspecto polêmico. 
Temos gente de todas as religiões. Respeitamos a cor, o credo, a religião, a orientação sexual de cada um. Mas todos têm que se portar de forma adequada, seguindo as regras do CTG. O valor familiar é muito grande no CTG, as gerações convivem aqui em harmonia. As regras de postura e comportamento influenciam na tua vida social e particular (Patroa).

Os entrevistados se referem ao CTG como a base de suas relações sociais, sugerindo ser este um resquício de constância e fixidez na sociedade líquidomoderna (Bauman, 2007), no qual se constrói e se opera a cooperação. Assim como Capataz e Vivente, Campeira narra que

aqui eu me sinto à vontade. A gente tem uma parceria grande, porque a gente trabalha em prol do CTG (...). Aqui é um encontro de amigos, fazendo chimarrão, é muito gostoso. Na hora de trabalhar todo mundo trabalha. A gente se doa pro CTG sem fins lucrativos.

Mesmo tratando-se de um elemento de fixidez, cabe a leitura de que o CTG se modifica e se reinventa (Luvizotto, 2010), de que suas regras continuam existindo e servindo de base para seus frequentadores, mas que se transformam à luz de novos valores que vem a fazer parte do contexto social em que se insere. Um exemplo foi a eleição da primeira Patroa do Mundo.

No que se refere aos elementos indexados, esses construíram quatro trajetórias diferentes. A primeira trajetória constitui-se daqueles que nasceram e foram criados no interior, próximos aos parentes mais velhos, aos valores e trabalhos rurais - Bolicheiro, Mãe de Prenda, Tropeiro, Campeira, Patroa e Vivente. A segunda constitui-se daqueles nascidos na capital e desde crianças levados ao CTG pelos pais ou avós, e incentivados a participar do movimento tradicionalista Primeira Prenda Adulta Regional, Guri de CTG, Prenda Farroupilha e Gaiteiro. A terceira constituiu-se por identificação com a tradição, a convite de amigos ou para levar os filhos - Segunda Prenda Juvenil e Capataz. A quarta trajetória constituiu-se a partir da paixão por alguém que já fazia parte da tradição gaúcha - Mulher Estancieira. Atualmente todos participam do CTG e tem como objetivo promover a continuidade do movimento tradicionalista.

Bolicheiro, Mãe de Prenda, Tropeiro, Campeira, Patroa e Vivente atribuem sua adesão ao tradicionalismo pelo fato de terem nascido no interior e, assim, terem naturalizado o comportamento e os valores "do campo". Mãe de Prenda afirma ter sido "criada dentro da tradição. Meu pai era agricultor, plantava, criava gado, aquela 
história toda de pessoa do interior". Para o Tropeiro, a tradição é algo "natural", por ele ter nascido no interior de Jaguari. Para a Primeira Prenda Adulta Regional, o Guri de CTG e a Prenda Farroupilha o tradicionalismo está presente no cotidiano pela presença da música, do chimarrão, das pilchas, entre outros elementos e também pela presença deles e da família no CTG.

A Prenda Farroupilha narra: "Quem me trouxe foram meus avós. Eles moravam aqui perto e depois se mudaram, mas a gente continua vindo, eu moro com eles, a gente comunga aqui". Nesse sentido, Mãe de Prenda conta que levou os filhos para participarem das invernadas, e agora leva a neta. Além disso, Mãe de Prenda relata que seus filhos, embora não produtores rurais nem pecuaristas, construíram sua história em torno do que aprenderam na tradição. Eles são veterinária, zootecnista e engenheiro agrícola, respectivamente. A Patroa tem família oriunda do interior, onde a mãe já participava dos concursos tradicionalistas de Primeira Prenda e o pai integrava o CTG de sua cidade de origem. Quando a família se mudou para Porto Alegre, logo associaram-se ao $35 \mathrm{CTG}$, no qual a patroa participa ativamente.

Vivente se associou recentemente ao $35 \mathrm{CTG}$, mas sua trajetória é ligada ao tradicionalismo desde a infância, quando seu pai fundou o primeiro CTG de uma pequena cidade do interior. A família, oriunda do meio rural, sempre cultivou o tradicionalismo e transmitiu ao filho o apreço pela tradição. Atualmente, Vivente participa principalmente das festas e bailes.

$\mathrm{Na}$ segunda trajetória, temos o relato do Gaiteiro, um jovem da capital que desde criança participou junto ao pai, que era músico tradicionalista, das atividades culturais do CTG. Hoje, o Gaiteiro trabalha em tempo integral no CTG e participa das invernadas como músico e no grupo de dança. A Primeira Prenda Regional Adulta participa do CTG desde criança, e faz parte da divisão cultural do CTG que aborda a história e a cultura gaúcha e prepara os participantes para as competições de Primeira Prenda e Primeiro Guri, com atividades como testes de conhecimento de História, concursos de declamação de poesia, dança e indumentária. Ela relata que sua mãe tem paixão por ser Mãe de Prenda e auxilia outras participantes a se prepararem para o concurso, quando a filha não está concorrendo.

$\mathrm{Na}$ terceira trajetória, Segunda Prenda Juvenil conta que "se eu pudesse iria todo dia pilchada para o colégio, mas as outras pessoas têm olhar diferente e a gente tem que respeitar [...]. A maioria das minhas amigas não gosta muito daqui, eu

(1) Revista Gestão \& Tecnologia, Pedro Leopoldo, v. 16, n. 1, p. 82-102, jan./abr. 201694 
convido, mas elas não aparecem". Nesse sentido, Segunda Prenda Juvenil e Prenda Farroupilha apresentam compreensão semelhante da participação na tradição, embora tenham chegado ao CTG por trajetórias diferentes. Prenda Farroupilha relata que, certa vez, quando seus avós ainda não tinham carro e sua avó havia Ihe dado seu primeiro vestido de Prenda ela usava o transporte coletivo urbano para ir até o CTG, no entanto não gostava de tal exposição, pois

Todo mundo ficava me olhando, como se eu fosse diferente, como se por causa da roupa eu fosse estranha. Algumas me olhavam com cara de quem gostava, mas outras não. Me perguntavam o que era aquela roupa, até foto dentro do ônibus eu já tirei de Prenda. Porque as pessoas não conhecem e acham estranho. Dai me perguntavam e eu tinha que explicar. Ai... Vergonha.

Capataz e a esposa se identificavam com alguns dos elementos do tradicionalismo, como a pilcha, o mate e a música, mas sentiam falta de compartilhar a tradição com outras pessoas, pois não possuíam em seus círculos de amigos e conhecidos pessoas que partilhassem dessa identificação com o tradicionalismo. Seu primeiro contato com o CTG foi quando a filha pediu um vestido de Prenda e para aprender a dançar. Ao levar a filha ao CTG, Capataz encontrou um ambiente com o qual se identificou, e pessoas para compartilhar seu amor pelo tradicionalismo. Capataz afirma "Agora se abriu um leque de amizades que a gente nem dá conta".

$\mathrm{Na}$ quarta trajetória, a Mulher Estancieira narra que começou a frequentar o CTG para se aproximar do namorado:

Eu comecei a frequentar o CTG depois que o conheci, aqui, porque antes eu não frequentava o CTG. Não gostava de usar vestido, me sentia muito grande, não sei, muito velha para isso, mas daí quando eu conheci ele, ele já andava todo pilchado, daí ele me falou que gostaria que eu usasse vestido e dai a gente começou a frequentar o 35, ele já era associado, daí eu me associei. Agora a gente frequenta bastante o CTG, minhas netas, elas fazem parte da invernada, elas são muito influídas a dançar. A gente gosta bastante daqui.

Nas trajetórias aparecem diversos elementos de permanência da tradição. As narrativas contemplam o chimarrão e a pilcha, de maneira unânime, e também o churrasco, a gamela, os avios do mate, a panela de ferro, o fogão de ferro, a trempa, o charque, o espeto, o encilho do cavalo, o laço, o cavalo parado, o galpão, o fogo de chão, a música, a dança, o jogo de bocha, o jogo de osso, o jogo de truco, o bolicho e o cavalo. Embora não citado pelos narradores, dada a naturalização do 
uso, o vocabulário gaúcho também é um elemento de permanência da tradição. Corresponde a isso, a naturalização dos saberes, quando se esquece de que houve aprendizagem e se acredita tratar-se de uma habilidade nata (Gorz, 2005).

As regras de comportamento e os valores, nas narrativas, também aparecem como indexados, pois estão em formato de documentos e tem de ser seguidos por todos, mas se relacionam com o aspecto não indexado de como isso acontece, de fato, nas histórias e trajetórias narradas.

Os concursos para escolha de Peões e Prendas, os concursos de dança e as cavalgadas, foram considerados elementos indexados, pois são parte da estrutura e do cronograma das atividades dos CTGs. Integram, inclusive, os principais objetivos do CTG, constituindo o meio pelo qual a tradição é transmitida e a forma como se manifestam as práticas e os ensinamentos. Este elemento indexado se relaciona aos não indexados quando as narrativas demonstram através de proposições descritivas, "como estes acontecimentos foram sentidos e experienciados" (Jovchelovitch \& Bauer, 2005, p. 106).

Foram identificados os seguintes elementos não indexados: desejo de perpetuar a tradição; amor pelas tradições e pelo movimento tradicionalista; aspirações acerca da representação do tradicionalismo através dos concursos; cooperação representada pelo compartilhamento, pela confiança mútua e pela responsabilidade; comportamento das pessoas que participam do movimento tradicionalista, e simplicidade do homem do campo como elemento relevante de alteridade e construção da identidade do grupo. No que se refere ao desejo de perpetuar a tradição, os entrevistados foram unânimes ao destacá-lo, juntamente com uma estima pela tradição e pelos elementos que permanecem no cotidiano dos narradores. Bolicheiro apresenta a promoção da continuidade da tradição como sua meta de vida, "a meta de vida é continuar com a tradição dos usos e costumes que foram deixados pelos nossos antepassados, nossos avós, homens mais velhos"; para tanto, em seu dia-a-dia faz uso da pilcha de peão "colete, bombacha, guaiaca, lenço vermelho no pescoço, bota, faca na cintura". Capataz afirma "A gente tenta sempre atrair a juventude, que é pra ver se não morre essa cultura que está aí há tantos anos", e comenta a respeito da terceira foto: "As lojas também ajudam a preservar a tradição, vendendo estas roupas onde (sic) as pessoas têm acesso aos trajes". 
Segunda Prenda Juvenil, por sua vez, mostra determinação ao promover continuidade da tradição, apresenta o desejo de transmitir o amor pela tradição para seus filhos e disseminar a cultura gaúcha para amigos. Ela conta que tem a intenção de chamar todos os amigos para comemorar seu aniversário no $35 \mathrm{CTG}$, pois nesse ano, a data coincidirá com a confraternização que o Centro organiza para festividades natalinas. Mãe de Prenda narra que seu pai transmitiu para os filhos o sentimento que tinha pela tradição, o conhecimento e os costumes gaúchos. Para dar continuidade, morando em Porto Alegre, participou do 35 CTG e incentivou seus filhos a participarem e, atualmente, incentiva os netos. Tropeiro e Mulher Estancieira contam que já estão levando as netas para o CTG, a adolescente participa da invernada e a mais nova vai assistir e fica brincando com as demais crianças. Ambos formam um casal e no dia em que foi realizada a entrevista, estavam na domingueira, baile que se inicia às 16 horas do domingo. Narraram o acontecimento no dia anterior, quando a neta mais nova insistiu em ir ao CTG. O trecho a seguir é parte da narrativa da Mulher Estancieira bastante orgulhosa com a atitude da neta:

Nós fomos buscar ela (a neta) ontem para ficar conosco no final de semana, ela mora com a mãe, daí a gente disse pra ela que não iríamos no baile porque estava chovendo e ela perguntou: e o que que eu vim fazer aqui se vocês não vão no baile?

Outro elemento não indexado que surgiu nas narrativas foi o sentimento relativo à felicidade, ao entusiasmo e à expectativa acerca do envolvimento em concursos de Peões e Prendas. Para aqueles que já participaram desses concursos, seja como personagem principal - Prenda e Peão, a que estavam concorrendo, seja como coadjuvante - pais, amigos e demais apoiadores do concorrente, este foi 0 momento mais importante de sua vida. Isso se evidencia, em especial, nas narrativas de Prenda Juvenil ao referir que nunca esquecerá o concurso, pois gosta muito de estudar a história do Rio Grande do Sul. Mãe de Prenda, por sua vez, diz que:

O momento que mais marcou em (sic) toda minha vida foi quando a minha filha concorreu à regional, então todo CTG vai e participa. As 30 regiões tradicionalistas do estado, cada CTG indica sua Prenda e elas vão lá e vão fazer provas escritas de conhecimentos gerais sobre a tradição; provas artísticas, provas artesanais, elas ficam todo um final de semana então dá uma ansiedade na gente porque tá todo mundo, toda família lá empenhada em ajudar e tal, porque é algo muito importante, tu está lá representando o 
teu CTG, é muito especial. [...] quando tu tem (sic) uma filha que se dedica se empenha tu te vira (sic) do avesso para ajudar também, tu faz (sic) tudo. Fica numa ansiedade quando elas vão declamar, quando elas vão fazer provas e tudo, né?! Tu faz (sic) o cabelo, a pilcha tem que estar impecável e cada vestido tem que ser diferente, um mais lindo que o outro.

Aqueles que ainda não participaram dos concursos afirmam que o momento mais importante da sua vida será quando participarem, ou tiverem um dos seus participando. Prenda Farroupilha destaca que "o momento mais importante da minha vida vai ser no concurso de Prenda. Ser Primeira Prenda vai ser esse o meu momento mais feliz e importante na tradição".

Como elementos não indexados, também foi tratada a percepção dos entrevistados de que o CTG é a extensão da família, é a extensão do lar, lotado de responsabilidade, amizade, confiança, lealdade e cooperação. Diante da imagem 02 , Bolicheiro contou que "no CTG todo mundo quer ajudar. Tem uma cozinheira, que até faleceu, e sempre que se elogiava a comida dela, ela dizia que colocava amor. $E$ é isso aí, até fico feliz de lembrar dela agora". Para Campeira, a continuidade da tradição através de sua família é muito significativa. Diz ela, "hoje eu já tenho netos e os netos vêm aqui pilchados. É uma terceira geração já, o que nos emociona muito". Em sua narrativa, Mãe de Prenda reforça: “Aqui no CTG é tudo muito familiar e por isso as pessoas parecem mais confiáveis. Agora mesmo a gente estava vendo a invernada mirim e a professora está de aniversário e daí todo mundo vai ajudar no galeto, no assado, todo mundo fazendo ou comprando bolo, todo mundo". Mãe de Prenda conta, ainda, outras situações cotidianas de confiança:

Se tu vai sair, tu avisa outro pai e diz que não pode levar hoje o gauchinho ou a prendinha, dai tu passa lá, pega, enche o carro e vem pro CTG, e cuida os filhos de todo mundo. São mais responsáveis. Daí tem aquela confiança, tu leva e cuida os meus filhos que na semana que vem eu vou com todo mundo e cuido os teus filhos. Todo mundo tem responsabilidade de um com o outro, uma confiança mútua, uma coisa boa de viver todo dia.

Diante da imagem 02, Prenda Farroupilha atém-se ao preparo da comida e à cooperação existente no CTG. Sua narrativa ilustra a cooperação como elemento não indexado. "Tem muita gente em piquete fazendo comida porque é muita gente, uma correria. Muita gente ajuda, todo mundo quer ajudar, às vezes eu oferecia ajuda para elas e outras (vezes) elas me pediam".

As contribuições de Gaulejac (2007) explicam a predisposição em cooperar narradas nos depoimentos. Para o autor, trata-se do encontro com o prazer da @@ Revista Gestão \& Tecnologia, Pedro Leopoldo, v. 16, n. 1, p. 82-102, jan./abr. 201698 
gratuidade, da troca e da partilha sem cálculo. De acordo com Dejours (2011), a cooperação só é possível se existir confiança mútua entre os atores, independente de possíveis relações hierárquicas. Nesse sentido, também se resgata Chanlat (2011) ao afirmar que o peso da história é sempre o "pano de fundo da relação", todos os indivíduos são conectados entre si pela compreensão comum de símbolos. Essa conexão se dá, em muito, graças a uma ritualização e a um processo de comunicação.

Os rituais relativos à tradição gaúcha servem como formas de mediar situações entre a competição e a cooperação, os quais foram explicitados nas narrativas sobre a participação dos entrevistados nos concursos, e mesmo na questão da eleição da patronagem do CTG. Embora exista competição entre os participantes, os rituais e as regras de conduta permitem que durante e após o momento da escolha, as pessoas continuem trabalhando juntas para um objetivo comum, o de manter e divulgar o tradicionalismo gaúcho.

Um aspecto que se fez evidente nas narrativas dos associados do 35 CTG remete à ideia de Sennett (2012, p.104) de que "Diferente não precisa ser melhor ou inferior; a sensação de ser diferente não precisa induzir a uma comparação invejosa". O conjunto dos entrevistados do 35 CTG demonstrou que elementos de construção de sua identidade partem da alteridade. Conforme a fala da Patroa:

Acho que o ponto alto do tradicionalismo foi a fundação do 35 , quando um grupo de jovens, em 1948, vindos do interior para estudar, sentiram falta dos valores do homem do campo. Nós valorizamos o homem do campo, diferente do caipira. (...) Cariados, remendando a roupa, para dizer que não tem roupa nova. Nós valorizamos o homem do campo: as atitudes, a palavra empenhada, o respeito, a cordialidade. Quem é tradicionalista de verdade é uma pessoa simples, sabe o objetivo dela. Tem muita gente que se aproveita do tradicionalismo para oportunidades, só que essas pessoas são passageiras. É uma seleção natural que acontece.

Tal alteridade, conforme ressalva dos entrevistados, não constitui preconceito ou consideração de superioridade. As narrativas denotam regozijo dos tradicionalistas diante da oportunidade de promover trocas culturais com pessoas de outros estados, como quando Campeira acompanhou um grupo de dança que foi vestido com trajes típicos gaúchos à praia de Copacabana, no Rio de Janeiro, e trocou com um grupo de cariocas uma cuia de chimarrão pela água de coco, e a partir desta troca, estabeleceu laços de amizade duradouros. 


\section{CONSIDERAÇÕES FINAIS}

Participar de uma cavalgada, confeccionar a própria indumentária, usar vestidos longos e rodados, abrir mão da vaidade do cetim e da transparência, usar bombachas e esporas, aprender a encilhar cavalo, tosquiar ovelha, cozinhar em uma panela de ferro, usar expressões do interior, compartilhar um chimarrão. O que parecia tão distante do cotidiano das cidades, de uma sociedade líquido-moderna, tal como pontua Bauman (2007), apresentam-se nas narrativas dos entrevistados como fontes de realização e entusiasmo. Onde? No Centro de Tradições Gaúchas, o lugar onde a tradição revigora, continua, se corporifica, encanta, apaixona, permanece.

O CTG, de acordo com os entrevistados, é um lugar onde a "incerteza", a "velocidade", a "ansiedade" não são convidadas. Para os narradores, o CTG é espaço onde a fluidez da sociedade líquido-moderna não está presente. Trata-se de um espaço onde o líquido é obrigado a contornar suas paredes.

Apaixonados pela tradição, os associados almejam serem promotores da continuidade das tradições gaúchas. Por isso, ao verem os filhos representado o tradicionalismo nos concursos - compartilhando e transmitindo os costumes gaúchos, sendo escolhidos para coordenar as atividades campeiras, para fazer parte do conselho, da patronagem, do grupo de dança, ou apenas do CTG, - trata-se de uma realização considerada como um dos momentos mais importantes da vida. $O$ desejo de transformar o CTG em uma família também é constante. Na investigação, percebeu-se que ele se corporifica ao se solidificarem laços de amizade, romance, cooperação e o compartilhamento de símbolos, o que também está em oposição à sociedade líquido-moderna (Bauman, 2007).

Pertencer, compartilhar, cooperar. "Quem está no CTG é por que gosta", afirmaram os entrevistados, trazendo não só o sentido de que não havia obrigação da doação que faziam de seu tempo, sua dedicação, seu esforço ao CTG, mas no sentido de que thes trazia felicidade e confiança, o conhecimento de que partilhavam entre si dos mesmos valores (símbolos), e que cooperavam na continuidade dos usos e costumes da tradição, mesmo quando há a interface desta cooperação com a competição dos concursos.

Acerca da existência de preconceitos, os narradores não os negam, apenas esclareceram que o tradicionalismo, seus rituais e elementos constitutivos,

$@$ @®® Revista Gestão \& Tecnologia, Pedro Leopoldo, v. 16, n. 1, p. 82-102, jan./abr. 2016100 
reinterpretam-se e reconstroem-se conforme seus princípios permitem e as mudanças da sociedade exigem. Compreende-se que os vestígios de solidez não significam o congelamento das práticas, mas a partilha de algo que lhes serve de pano de fundo para a construção das relações sociais. E vão além, estendendo-se para a esfera privada, para o mundo urbano, para os diversos contextos da vida dos entrevistados.

A cooperação é reconhecida como ponto central de participação no CTG, configura-se como elemento comum entre as trajetórias, vinculando-se aos elementos não indexados, em que, através da construção social do contexto do tradicionalismo, os entrevistados executam e reelaboram rituais e mantém valores comuns, fonte de identificação e meio para a cooperação. O tradicionalismo ainda aparece nas trajetórias como elemento de continuidade dos valores do campo e da simplicidade na Capital do Estado. O contraste apresentado adquire a característica de fornecer a base de relações sociais para que os sujeitos lidem com a vida líquidomoderna e com o tempo do curto prazo da sociedade atual.

A pesquisa exploratória permitiu conhecer quais são os elementos, alguns dos rituais e a forma como estes operam no contexto do caso do 35 CTG. Através dos elementos indexados e não indexados identificados na pesquisa, tornou-se palpável o contexto no qual encontramos os vestígios da cooperação e da solidez. A riqueza dos dados e da experiência de pesquisa no 35 CTG não se esgota neste estudo; pelo contrário. Um possível prosseguimento do presente estudo poderia explorar os elementos das narrativas que surgiram e investigá-los num contexto mais amplo, e sob a influência da passagem do tempo cronológico.

\section{REFERÊNCIAS}

Amaral, S. C. de S., Pinho, L. G., Martinez, S. A., \& Nascimento, G. do. (2014). Modernidade e Individualismo sob a Ótica de Bauman e Giddens. InterSciencePlace, 29(1), 138-175.

Bauman, Z. (2007). Vida líquida. Rio de Janeiro: Jorge.

Bauman, Z. (2011). A vida em fragmentos: sobre a ética pós-moderna (A. Erneck, Tad.). Rio de Janeiro: Jorge Zahar.

Chanlat, J. F. (2011). Gestão empresarial: uma perspectiva antropológica (L. Gillon, Trad.) São Paulo: Cengage Learning.

Dejours, C. (2011). Da Psicopatologia à Psicodinâmica do Trabalho (3a ed.). In L. Selma, \& I. S. Laerte (Orgs.). Rio de Janeiro: Editora Fiocruz/Brasília: Paralelo 15. 
Deleuze, G. (2005). Diferença e repetição. Rio de Janeiro: Ed. Graal.

Gaulejac, V. (2007). Gestão como doença social. São Paulo: Ideias e Letras.

Gorz, A. (2005). O imaterial: conhecimento, valor e capital. São Paulo: Annablume.

Jovchelovitch, S., \& Bauer, M. W. (2005). Entrevista narrativa. In M. W. Bauer, \& G.

Gaskell. Pesquisa qualitativa com texto, imagem e som. (12a ed., P. Guareschi, Trad.). Petrópolis, RJ: Vozes.

Haroche, C. (2015). O sujeito diante da aceleração e da ilimitação contemporâneas. Educ. Pesqui., 41(4), 851-862.

Luvizotto, C. K. (2010). As tradições gaúchas e sua racionalização na modernidade tardia. São Paulo: Cultura Acadêmica.

Ribeiro, D. (1997). O povo brasileiro: evolução e o sentido do Brasil. São Paulo: Companhia das Letras.

Sennett, R. (2012). Juntos. Rio de Janeiro: Record.

Silva, R. B., Mendes, J. P. S., \& Alves, R. dos S. L. (2015). O Conceito de Líquido em Zygmunt Bauman: Contemporaneidade e Produção de Subjetividade. Athenea Digital, 15(2), 249-264.

Stake, R. (2005). The art of case study research. Thousand Oaks, CA: Sage Publications.

Zarur, A. P., \& Campos, J. L. de. (2015). A juventude como valor na modernidade líquida. Temática, 1, 41-51. 